\title{
Effects of financial support on treatment of adolescents with growth hormone deficiency: a retrospective study in Japan
}

\author{
Eri Maeda', Takahiro Higashi ${ }^{2,3^{*}}$, Tomonobu Hasegawa ${ }^{3}$, Susumu Yokoya ${ }^{3}$, Takahiro Mochizuki ${ }^{3}$, Tomohiro Ishii ${ }^{3}$, \\ Junko Ito ${ }^{3}$, Susumu Kanzaki ${ }^{3}$, Akira Shimatsu ${ }^{3}$, Koji Takano ${ }^{3}$, Toshihiro Tajima ${ }^{3}$, Hiroyuki Tanaka ${ }^{3}$, Yusuke Tanahashi ${ }^{3}$, \\ Akira Teramoto ${ }^{3}$, Toshiro Nagai ${ }^{3}$, Kunihiko Hanew ${ }^{3}$, Reiko Horikawa ${ }^{3}$, Toru Yorifuji ${ }^{3}$, Naohiro Wada ${ }^{3}$ \\ and Toshiaki Tanaka ${ }^{3}$
}

\begin{abstract}
Background: Treatment costs for children with growth hormone $(\mathrm{GH})$ deficiency are subsidized by the government in Japan if the children meet clinical criteria, including height limits (boys: $156.4 \mathrm{~cm}$; girls: $145.4 \mathrm{~cm}$ ). However, several funding programs, such as a subsidy provided by local governments, can be used by those who exceed the height limits. In this study, we explored the impacts of financial support on GH treatment using this natural allocation.

Methods: A retrospective analysis of 696 adolescent patients (451 boys and 245 girls) who reached the height limits was conducted. Associations between financial support and continuing treatment were assessed using multiple logistic regression analyses adjusting for age, sex, height, growth velocity, bone age, and adverse effects.

Results: Of the 696 children in the analysis, 108 (15.5 \%) were still eligible for financial support. The proportion of children who continued GH treatment was higher among those who were eligible for support than among those who were not $(75.9 \%$ vs. $52.0 \%, P<0.001)$. The odds ratios of financial support to continuing treatment were 4.04 (95\% confidence interval [Cl]: 1.86-8.78) in boys and 1.72 (95\% Cl: 0.80-3.70) in girls, after adjusting for demographic characteristics and clinical factors.

Conclusions: Financial support affected decisions on treatment continuation for children with GH deficiency. Geographic variations in eligibility for financial support pose an ethical problem that needs policy attention. An appropriate balance between public spending on continuation of therapy and improved quality of life derived from it should be explored.
\end{abstract}

Keywords: Public funding, Health insurance, Children with special health care needs, Japan

\section{Background}

Biosynthetic human growth hormone $(\mathrm{GH})$ is very expensive. The annual cost for one child weighing $30 \mathrm{~kg}$ is reported to be approximately US $\$ 15,000$ to $\$ 24,000$ [1-3]. Although most of the costs are covered by public health insurance or reimbursed by governments in many

\footnotetext{
* Correspondence: thigashi@ncc.go.jp

${ }^{2}$ Division of Health Services Research, Center for Cancer Control and Information Services, The National Cancer Center, 5-1-1 Tsukiji, Chuo-ku, Tokyo 104-0045, Japan

${ }^{3} \mathrm{GH}$ Treatment Study Committee, The Foundation for Growth Science,

5-1-16 Hongo, Bunkyo-ku, Tokyo 113-0033, Japan

Full list of author information is available at the end of the article
}

countries [4], the extent to which public funding should be used for support involves ethical issues, resulting in different policies $[1,4]$. Little is known about the impact of financial support on decision-making for treatment of children with growth hormone deficiency (GHD).

Important lessons may be learned by studying the case of Japan, where the level of subsidy for treatment depends purely on the patient's geographic location (Fig. 1). Generally, Japan provides universal health insurance coverage to its citizens up to $70 \%$ of the medical charges, with the remainder paid by patients [5]. However, for some rare diseases, including GHD, national 


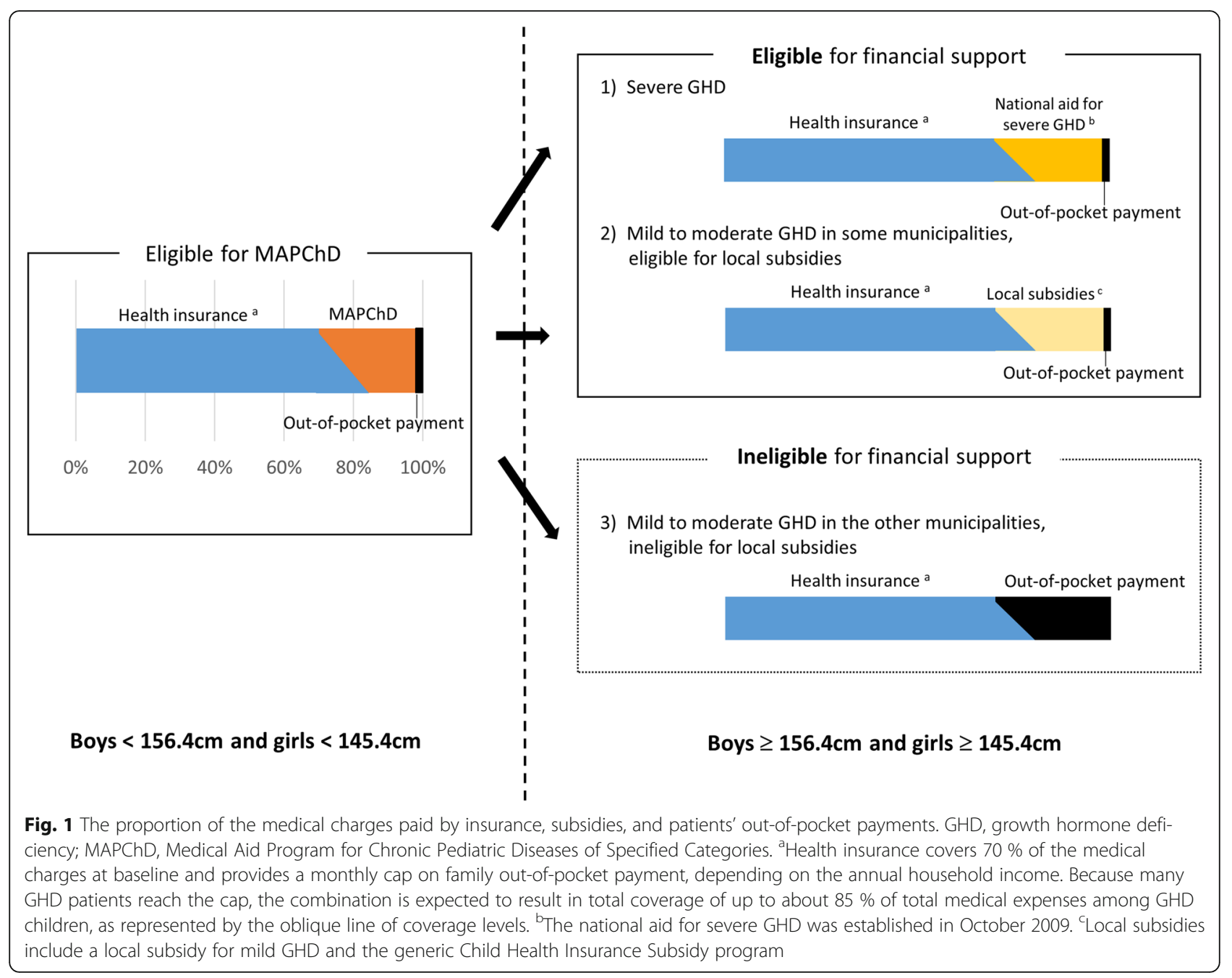

and local subsidies provide financial support for patients' out-of-pocket payments. Doctors ensure that patients understand what programs are available.

The primary program to assist children with GHD is the Medical Aid Program for Chronic Pediatric Diseases of Specified Categories (MAPChD) [6, 7]. This program covers most of the copayments for children with GHD who meet certain criteria. These criteria include height limits up to a -2.5 standard deviation score (SDS) of the height for near-adults (i.e., 17.5-year-old children); specifically, $156.4 \mathrm{~cm}$ for boys and $145.4 \mathrm{~cm}$ for girls. Another program, established by the national government in October 2009, is the aid for severe GHD, which covers treatment costs for patients who exceed the eligible height limits for MAPChD [8]. Local governments operate two other programs. One is a subsidy offered by some municipalities for children with mild GHD who do not meet either of the subsidy criteria defined by the national government. The other is the generic Child Health Insurance Subsidy program, which is available in all 1742 municipalities in Japan. This program covers medical copayments of children who live in these municipalities, regardless of their health. While the MAPChD uniformly covers every patient in Japan, the eligibility criteria and benefits of local programs vary across municipalities [9]. Some municipalities cover children up to only 3 years of age, whereas others offer coverage up to 22 years of age. Copayments can range from free to a few dollars per visit, depending on household income. Therefore, some children with GHD who exceed the MAPChD height limit can receive financial support, but others cannot, depending on where they live.

The present study used this geographic variation in subsidy access as a natural experiment and examined the impacts of financial support on GH treatment. Based on earlier works regarding costs and treatment-seeking behavior [10-18], we hypothesized that children with GHD who were eligible for financial support from local programs were more likely than those who were ineligible for any financial support to continue $\mathrm{GH}$ treatment even after they reached the height limit and were no longer subsidized by the MAPChD. Insurance coverage 
generally has positive effects on the use of pediatric specialty care in the United States [10-16], but health economic literature on pediatric care is very limited in Japan $[17,18]$. The aims of the study were to evaluate the relationship between financial support and patient behavior among children with GHD and to reveal possible effects of the geographical variation of local subsidy programs on access to specialty care among children in Japan.

\section{Methods}

\section{Study population}

The study population consisted of children with GHD registered in the Foundation for Growth Science database [19]. The Foundation for Growth Science works closely with the government to regulate $\mathrm{GH}$ use in Japan. Until 1997, registration with the foundation was required to apply for MAPChD, but this requirement has been discontinued. Currently, clinicians across the nation voluntarily register patient data in the database, and the registration rate of children with GHD is estimated to be $30 \%$ [19]. The registry database includes patient age, sex, clinical data (e.g., height, weight, bone age, puberty status, results of GH tests, adverse effects), treatment protocols, whether patients continued or stopped GH, and the locations of medical institutions.

Registry data included 2471 children who reached the MAPChD height limits (for boys, $156.4 \mathrm{~cm}$; for girls, $145.4 \mathrm{~cm}$ ) from January 2001 to May 2013. After excluding children who did not meet the clinical criteria for MAPChD eligibility in the first place, we analyzed data on 696 children ( 451 boys and 245 girls) who met the criteria at the first registration and then became ineligible because they reached the height limits. Criteria for MAPChD are as follows. The criteria for starting GH in cases without organic abnormalities are height $\leq-2.5$ SDS; insulin-like growth factor1 (IGF-1) $<200 \mathrm{ng} / \mathrm{ml}$ or $<$ $150 \mathrm{ng} / \mathrm{ml}$ in children $<5$ years old; and peak GH in provocative test $\leq 6 \mathrm{ng} / \mathrm{ml}$. The criteria for starting $\mathrm{GH}$ in cases with organic abnormalities are height $\leq-2.0$ SDS or growth velocity $(\mathrm{GV}) \leq-1.5 \mathrm{SDS}$ for 2 years; and peak GH in provocative test $\leq 3 \mathrm{ng} / \mathrm{ml}$. The criteria for continuing $\mathrm{GH}$ in the first treatment year are $\mathrm{GV} \geq 6.0 \mathrm{~cm} /$ year or $\mathrm{GV}$ increment $\geq 2.0 \mathrm{~cm} /$ year. The criterion for continuing $\mathrm{GH}$ in the second year and after is $\mathrm{GV} \geq 3.0 \mathrm{~cm} /$ year.

\section{Financial support for patients taller than the MAPChD height limits}

We categorized children who met the criteria for severe GHD and reached the MAPChD height limit after October 2009, when the aid for severe GHD was established, as those who were eligible for the national subsidy for severe GHD. Criteria for severe GHD included a peak $\mathrm{GH}$ in provocative tests of $\leq 3 \mathrm{ng} / \mathrm{ml}$ in children with height $\leq-2.0$ SDS or a peak $\mathrm{GH} \leq 1.8 \mathrm{ng} / \mathrm{ml}$ in adults.

We collected information on the local subsidy programs for the children in the sample, including the presence or absence of programs. If a program existed, we recorded the eligibility criteria either by searching program web sites or by contacting the Ministry of Health, Labour and Welfare, prefectures, and municipalities by telephone or e-mail. Collating the age of each patient and the eligibility criteria for the local subsidies in each municipality, we categorized children into two groups (eligible and ineligible), depending on whether they were eligible for at least one of the national or local subsidies.

\section{Data analyses}

Statistical comparisons were carried out to compare the variables between patients who were eligible or ineligible for financial support, using Student's $t$ tests, two-group variance-comparison tests, Welch's $t$ tests, Wilcoxon's rank sum tests, chi-square tests, and Fisher's exact tests, according to the type of outcome variables and distribution of the variables. Multiple logistic regression analysis was used to assess the relation of financial support to the continuation of $\mathrm{GH}$ treatment, after adjusting for possible confounders: age in years, sex, height (on a standard deviation scale; SDS), growth velocity (centimeters per year), bone age in years, adverse effects (yes/no), and when patients reached height limits (before or after October 2009, when the national subsidy for severe GHD was implemented). We assessed interaction terms between sex and financial support and between sex and bone age to account for possible differences in the effects of financial support and bone age on the continuation of therapy between boys and girls.

We also conducted sensitivity analyses to test the robustness of our findings. First, we removed bone age from the regression model, because 76 values were missing for bone age and because age and bone age were moderately correlated (Pearson's correlation coefficient: $0.53, p<0.001)$. Second, we included pubertal status (pre- or post-puberty) in the regression model. Finally, to address the possibility that treatment decisions were changed after the data were registered, we excluded children from the treated group if they were not registered as treated patients in the following year. All analyses were performed using Stata12-SE (StataCorp LP, College Station, TX, USA).

\section{Results}

Of the 696 children, 42 (6.0\%) were eligible for the national subsidy for severe GHD. Regarding local subsidies, medical institutions of the 696 children were distributed across 155 municipalities $(8.9 \%$ of the total 1742 municipalities in Japan). Of these children, 69 children in 22 
municipalities and three children in two municipalities were assumed to meet criteria for the local Child Health Insurance Subsidies and the local subsidy for mild GHD, respectively. There were six children who were eligible for both of the national and local subsidies. Overall, 108 children (15.5\%) were categorized as eligible for financial support after they reached the MAPChD height limits.

Table 1 lists the characteristics of the children. The proportion of children who continued $\mathrm{GH}$ was higher among those with financial support than among those without (75.9 \% vs. $52.0 \%, p<0.001$, Fig. 2). The

Table 1 Characteristics of the 696 patients and additional financial support after reaching the height limit

\begin{tabular}{|c|c|c|c|}
\hline \multirow[t]{2}{*}{ Variables } & \multirow{2}{*}{$\begin{array}{l}\text { Ineligible } \\
(n=588)\end{array}$} & \multirow{2}{*}{$\begin{array}{l}\text { Eligible }^{a} \\
(n=108)\end{array}$} & \multirow{2}{*}{$\begin{array}{l}p \\
\text { value }^{\text {b }}\end{array}$} \\
\hline & & & \\
\hline \multicolumn{4}{|l|}{ GH treatment, $n(\%)$} \\
\hline Stopped & $282(48.0)$ & $26(24.1)$ & \multirow[t]{2}{*}{$<0.001$} \\
\hline Continued & $306(52.0)$ & $82(75.9)$ & \\
\hline \multicolumn{4}{|l|}{ Sex, $n(\%)$} \\
\hline Girls & $196(33.3)$ & $49(45.4)$ & \multirow[t]{2}{*}{0.016} \\
\hline Boys & $392(66.7)$ & $59(54.6)$ & \\
\hline \multicolumn{4}{|l|}{ Age, y } \\
\hline Mean (SD) & $14.8(1.4)$ & $14.4(1.3)$ & 0.0015 \\
\hline Girls & $13.7(1.0)$ & $13.7(1.0)$ & 0.62 \\
\hline Boys & $15.4(1.2)$ & $15.0(1.1)$ & 0.017 \\
\hline \multicolumn{4}{|l|}{ Height SDS } \\
\hline Median & -1.59 & -1.525 & \multirow[t]{2}{*}{0.16} \\
\hline (Interquartile range) & $(-1.89$ to -1.21$)$ & $(-1.81$ to -1.07$)$ & \\
\hline \multicolumn{4}{|l|}{ Growth velocity, cm/y } \\
\hline Mean (SD) & $6.7(2.9)$ & $6.5(2.5)$ & \multirow[t]{2}{*}{0.46} \\
\hline Bone age, y & $(n=520)$ & $(n=100)$ & \\
\hline Mean (SD) & $13.1(1.4)$ & $12.9(1.2)$ & 0.13 \\
\hline Girls & $12.1(1.1)$ & $12.2(1.0)$ & 0.82 \\
\hline Boys & $13.6(1.3)$ & $13.6(0.9)$ & \multirow[t]{2}{*}{0.56} \\
\hline Puberty status, $n$ (\%) & $(n=562)$ & $(n=108)$ & \\
\hline Pre-puberty & $68(12.1)$ & $17(15.7)$ & \multirow[t]{2}{*}{0.30} \\
\hline Post-puberty & $494(87.9)$ & $91(84.3)$ & \\
\hline \multicolumn{4}{|l|}{ Adverse effects, $n$ (\%) } \\
\hline No & $560(95.2)$ & $105(97.2)$ & \multirow[t]{2}{*}{0.46} \\
\hline Yes & $28(4.8)$ & $3(2.8)$ & \\
\hline \multicolumn{4}{|c|}{ When patients reached height limit, $n(\%)$} \\
\hline Before October 2009 & $437(74.3)$ & $9(8.3)$ & \multirow[t]{2}{*}{$<0.001$} \\
\hline October 2009 and after & $151(25.7)$ & $99(91.7)$ & \\
\hline
\end{tabular}

GH growth hormone, SD standard deviation, SDS standard deviation score aEligible for at least one of the national or local programs of financial support after the child exceeded the height limit defined by the Medical Aid Program for Chronic Pediatric Disease of Specified Categories

${ }^{b}$ Chi-square tests, two-tailed $t$-tests, Wilcoxon rank sum tests, Welch $t$-tests, or Fisher's exact tests percentage of children who were eligible for financial support was significantly higher among girls.

As shown in Table 2, multiple logistic regression analysis revealed that eligibility of financial support was associated with 4.04 (95\% confidence interval [CI]: 1.86-8.78) times the odds of continuing treatment among boys, and the corresponding odds among girls were as small as 1.72 (95\% CI: 0.80-3.70). The percentages of those who continued $\mathrm{GH}$ treatment were $76.7 \%$ among those with financial support and $54.7 \%$ among those without, after adjusting for the previously mentioned factors (80.9 \% vs. $52.9 \%$ among boys and $69.4 \%$ vs. $58.0 \%$ among girls).

Table 3 shows the results of the sensitivity analyses when we removed bone age from the baseline model, when we added pubertal status to the model, and when we excluded the cases in which treatment decisions might have changed after the data were registered. The ORs of the first and second analyses are similar to those in the original model. In the third analysis, 136 patients were registered to continue $\mathrm{GH}$ but were not registered as being treated in the following year. When we excluded them as unknown cases, the ORs were 2.91 and 2.37 in boys and girls, respectively.

\section{Discussion}

Our findings revealed that $76.7 \%$ of children with GHD who were financially supported continued treatment even after they exceeded the government-defined height criteria, whereas only $54.7 \%$ of those who were not supported continued GH. Although previous studies have shown that financial support generally promotes treatment seeking in patients [10-18], this study is the first to assess the effects of financial support on $\mathrm{GH}$ treatment. Importantly, the percentage of children with GHD who reached the height limit and stopped treatment for reasons other than financial factors was less than $25 \%$. Given the strong impact of public funding on treatment decisions, the clinical criteria for MAPChD eligibility of GHD patients must be carefully considered and based on concrete evidence. Although direct generalization to other countries may be difficult because of the different health care systems, our findings can support policy discussion not only in Japan but also in other countries that financially support GH treatment [4].

In the present sample, financial support had larger effects on boys than on girls. Differences in clinical characteristics (i.e., hormonal levels [20] or treatment response [21]) might be possible, although we made adjustment for the available clinical factors. Another possibility is the gender difference in attitudes toward height. Our data might have reflected patients' behavior based on societal preferences for tall males, as shown in earlier works [22-24]. However, a more likely reason is 


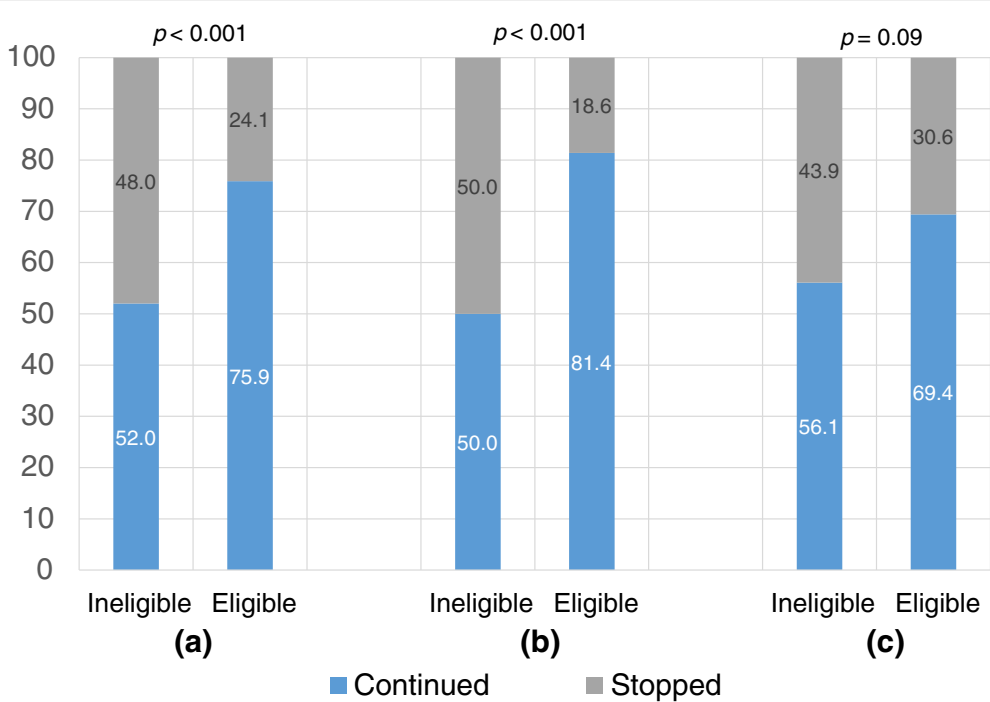

Fig. 2 The proportion of patients who continued treatment, by financial support status and by sex: a present sample; b boys; c girls

the age criteria for the local Child Health Insurance Subsidies. Most municipalities provide a subsidy up to 15 years of age, at which point girls typically experience a natural slowing of growth in height, whereas boys are still rapidly growing [25]. This fact may have influenced the girls' decisions to discontinue therapy. Although we cannot test this hypothesis because of the limited number of sample patients in respective municipalities that had different criteria, consideration of the sex differences in growth may be needed when setting the criteria for future subsidies.

Our results are consistent with those of prior studies describing health care improvement among children with special health care needs [26] after enrollment in the State Children's Health Insurance Program in the United States [10-15]. Both in specific populations, such as patients with asthma [12,13], and in heterogeneous populations with a wide range of health statuses, such as children with special health care needs $[11,14,15]$, a decline in unmet health care needs and an increase in utilization were observed. A study using data from the RAND Health Insurance Experiment [16] showed a $36 \%$ decline in outpatient episodes for chronic care among children assigned to cost-sharing plans, compared with those on a free care plan.

The present findings also agree with previous research in Japan, although the few available studies were restricted to general care. These studies showed that local subsidy programs directed parental attitudes toward immediate visit [17] and increased the probability of receiving treatment, especially among children aged between 7 and 12 years [18]. With regard to specialty care for children with rare diseases, the current study was the first to describe the association between local subsidy programs and care-seeking behavior. Although little attention has been paid to geographical differences in financial support in Japan, we found that $22 \%$ more patients stopped treatment because of a lack of financial support compared with patients that had financial support. This geography-based inequality raises an ethical concern. Currently, MAPChD [6, 7] supports out-ofpocket payment of children with 704 chronic diseases [27] and defines subsidy criteria for some of the diseases, such as GHD. In view of the previous results that parental attitudes toward severe symptoms of colds were not significantly different regardless of the level of subsidies [17], caution should be taken in applying the present results to other disease that have different clinical features and payment amounts. However, this study provides policy-makers with an important reference to resolve this geographic gap.

Establishing evidence-based criteria for public funding in $\mathrm{GH}$ treatment is an area for future research. The current height limit does not seem to meet patients' needs. The mean height velocity of the present population was $6.7 \mathrm{~cm} /$ year, and the mean bone ages were 13.6 and 12.1 years old in boys and girls, respectively. According to the longitudinal data of Japanese school children [25], most children in the present sample were at peak height velocity and could grow closer to normal heights. However, a previous cohort study showed that patients who stopped treatment early spontaneously gained 0.4 SDS after the end of treatment, possibly because of the difficulty in distinguishing GHD from pubertal delay [28]. Determining endpoints of treatment is difficult in the majority of patients without severe GHD [1]. Treatment appears to be effective $[2,29,30]$ and safe [31] in many cases, but careful follow-up surveys for 
Table 2 Multiple logistic regression analysis for factors related to treatment decisions $(n=620)$

\begin{tabular}{|c|c|c|}
\hline Variables & OR & $95 \% \mathrm{Cl}$ \\
\hline \multicolumn{3}{|l|}{ Eligibility for financial support ${ }^{\mathrm{a}}$} \\
\hline Ineligible & \multicolumn{2}{|c|}{ Reference } \\
\hline Eligible (girls) & 1.72 & $0.80-3.70$ \\
\hline Eligible (boys) & 4.04 & $1.86-8.78$ \\
\hline \multicolumn{3}{|l|}{$\operatorname{Sex}^{\mathrm{b}}$} \\
\hline Girls & \multicolumn{2}{|c|}{ Reference } \\
\hline Boys & 1.88 & $1.00-3.51$ \\
\hline \multicolumn{3}{|l|}{ Age, y } \\
\hline Each additional year older & 0.64 & $0.51-0.79$ \\
\hline \multicolumn{3}{|l|}{ Height SDS } \\
\hline Each additional SDS increase & 0.65 & $0.43-0.99$ \\
\hline \multicolumn{3}{|l|}{ Growth velocity, cm/y } \\
\hline Each growth velocity increase & 1.04 & $0.97-1.12$ \\
\hline \multicolumn{3}{|l|}{ Bone age, $y^{c}$} \\
\hline Each additional year older (girls) & 0.69 & $0.52-0.93$ \\
\hline Each additional year older (boys) & 0.90 & $0.74-1.09$ \\
\hline \multicolumn{3}{|l|}{ Adverse effects } \\
\hline No & \multicolumn{2}{|c|}{ Reference } \\
\hline Yes & 0.61 & $0.28-1.32$ \\
\hline \multicolumn{3}{|l|}{ When patients reached the height limit } \\
\hline Before October 2009 & \multicolumn{2}{|c|}{ Reference } \\
\hline October 2009 and after & 0.84 & $0.56-1.26$ \\
\hline \multicolumn{3}{|c|}{$\begin{array}{l}\mathrm{Cl} \text { confidence interval, } O R \text { odds ratio } \\
\text { aEligibility for at least one of the national or local programs of financial } \\
\text { support after exceeding the height limit defined by the Medical Aid Program } \\
\text { for Chronic Pediatric Disease of Specified Categories } \\
\text { b Comparing boys at the bone age of } 15 \mathrm{y} \text { to girls at the bone age of } 13 \mathrm{y} \text {, without } \\
\text { financial support (comparing different bone ages due to differential centering for } \\
\text { the variable) } \\
\text { cBone age was centered at } 13 \mathrm{y} \text { in girls and at } 15 \mathrm{y} \text { in boys }\end{array}$} \\
\hline
\end{tabular}

adult height would provide more information about the extent to which the public should support patients with GHD.

Furthermore, constructing cost-effectiveness models based on pertinent evidence regarding adult height, other health outcomes, and quality of life may help in confirming or revising current criteria although so far, evidence based on long-term follow-up is limited [28,
32]. Previous work has calculated the incremental cost effectiveness of $\mathrm{GH}$ treatment at approximately $£ 6000$ (about US \$9000, using a 2002 exchange rate) per centimeter gained in adult height [33]. In addition to height, we should also include metabolic effects [34, 35], psychological effects [36-39], and short-term [40] and long-term quality of life [41-44], all of which remain inconclusive and need further research.

This study has several limitations. First, the use of a nonmandatory registry database could have caused a selection bias. Although cases of discontinuation might be less likely to be registered than those of continuation, there is no reason to consider the registry to be affected by the recipient status of financial support. Second, the registry did not contain socio-economic information about the patients. Future surveys should address the influence of these factors for in-depth understanding of the process of patients' decision-making. Third, some patients may have been misclassified as eligible for local subsidies. We determined the presence or absence of local subsidies based on the locations of the treatment providers, because the data set did not contain patients' residences. Also, we did not account for differences in benefits across municipalities, income-based eligibility limit, or the presence of other subsidies, such as subsidies for single parents or for the disabled [45]. However, these factors would not have largely influenced our results. Any misclassification caused by substituting patients' residences with locations of medical institutions would have had a negligible effect on the results because the eligibility criteria defined by neighboring municipalities are usually similar under financial help by prefectures [9]. The difference in benefits is relatively small compared with the high cost of GH. Furthermore, misclassification of financial support eligibility criteria in this study would likely result in the underestimation of the relationship in two ways. Income-based eligibility limit would prevent patients who otherwise satisfy criteria from receiving support, making some patients who appeared to be "eligible" for support more likely to have discontinued therapy. Similarly, the presence of other subsidies not considered in this study may have increased the likelihood of patients continuing therapy despite being categorized as "ineligible".

Table 3 Sensitivity analyses of the odds ratio of financial support to continuing treatment

\begin{tabular}{|c|c|c|c|c|}
\hline & \multicolumn{2}{|l|}{ Boys } & \multicolumn{2}{|l|}{ Girls } \\
\hline & OR & $95 \% \mathrm{Cl}$ & OR & $95 \% \mathrm{Cl}$ \\
\hline Base model $(n=620)$ & 4.04 & $1.86-8.78$ & 1.72 & $0.80-3.70$ \\
\hline Excluding bone age $(n=696)$ & 4.31 & $2.05-9.03$ & 1.99 & $0.95-4.17$ \\
\hline Including puberty status ( $n=602$ ) & 4.11 & $1.88-8.96$ & 1.76 & $0.81-3.80$ \\
\hline Excluding patients not registered in the following year $(n=491)$ & 2.91 & $1.21-6.97$ & 2.37 & $0.99-5.67$ \\
\hline
\end{tabular}




\section{Conclusions}

This study revealed that financial support affects decision-making for treatment of adolescents with GHD. Because cost is a major consideration in $\mathrm{GH}$ treatment, future cost-effectiveness analyses addressing quality-oflife changes as well as physical and psychological improvement are needed to establish more evidence-based criteria for public funding.

\section{Abbreviations}

GH: Growth hormone; GHD: Growth hormone deficiency; MAPChD: Medical Aid Program for Chronic Pediatric Diseases of Specified Categories; OR: Odds ratio; SDS: Standard deviation score

\section{Acknowledgements}

The authors thank Prof. Yasuki Kobayashi, Department of Public Health, Graduate School of Medicine, The University of Tokyo, for his expert advice and help with this study. The authors thank all the participating clinicians in the Japanese GH registry for their continuous support in data collection.

\section{Funding}

This study was funded by Grant-in-Aid for JSPS Fellows (26-1591). The funders had no role in study design, data collection and analysis, decision to publish, or preparation of the manuscript.

\section{Availability of data and materials}

The data are available from the Foundation for Growth Science for researchers who are approved to use them by the Foundation committee.

\section{Authors' contributions}

EM conceptualized and designed the study, carried out the analyses, drafted the initial manuscript, and approved the final manuscript as submitted. $\mathrm{TH}$ carried out the analyses, reviewed and revised the manuscript, and approved the final manuscript as submitted. $T$ designed the data collection instruments, coordinated and supervised data collection, critically reviewed the manuscript, and approved the final manuscript as submitted. All the other authors critically reviewed the manuscript, approved the final manuscript as submitted, and agree to be accountable for all aspects of the work.

\section{Competing interests}

The authors declare that they have no competing interest.

\section{Consent for publication}

Not applicable.

\section{Ethics approval and consent to participate}

The study was reviewed and approved by the institutional ethics committee of the University of Tokyo (number 10138, approved on May 29, 2013). The study design was a secondary data analysis of the Foundation for Growth Science database. Patients who did not consent to have their information used in research were not registered.

\section{Author details}

'Department of Environmental Health Sciences, Akita University Graduate School of Medicine, 1-1-1 Hondo, Akita-shi, Akita 010-8543, Japan. ²Division of Health Services Research, Center for Cancer Control and Information Services, The National Cancer Center, 5-1-1 Tsukiji, Chuo-ku, Tokyo 104-0045, Japan. ${ }^{3} \mathrm{GH}$ Treatment Study Committee, The Foundation for Growth Science, 5-1-16 Hongo, Bunkyo-ku, Tokyo 113-0033, Japan.

Received: 3 April 2016 Accepted: 15 October 2016

Published online: 21 October 2016

\section{References}

1. Allen DB, Fost N. hGH for short stature: ethical issues raised by expanded access. J Pediatr. 2004;144:648-52

2. Radcliffe DJ, Pliskin JS, Silvers JB, Cuttler L. Growth hormone therapy and quality of life in adults and children. Pharmacoeconomics. 2004;22:499-523.
3. Ministry of Health, Labour and Welfare. Various information of medical fee. Drug information browsing system. http://www.iryohoken.go.jp/ shinryohoshu/yakuzaiMenu/. Accessed 28 Apr 2015 (in Japanese)

4. Tanaka T. Global situation of growth hormone treatment in growth hormone- deficient children. Horm Res. 1999;51:75-80.

5. Ikegami $N$, Yoo BK, Hashimoto $H$, Matsumoto $M$, Ogata $H$, et al. Japanese universal health coverage: evolution, achievements, and challenges. Lancet. 2011;378:1106-15.

6. Gu YH, Kato T, Harada S, Sato Y, Kakee N. Medical aid program for chronic pediatric diseases of specified categories in Japan: current status and future prospects. Pediatr Int. 2008;50:376-87.

7. Ministry of Health, Labour and Welfare. Shoni mansei tokutei shikkan chiryo kenkyu jigyo no gaiyo [Overview of Medical aid program for chronic pediatric diseases of specified categories]. http://www.mhlw.go.jp/bunya/ kodomo/boshi-hoken05/. Accessed 28 Apr 2015 (In Japanese).

8. Japan Intractable Diseases Information Center. What is an intractable disease? http://www.nanbyou.or.jp/english/index.htm. Accessed 28 Apr 2015.

9. Ministry of Health, Labour and Welfare. Nyuyoji-tou iryohi ni taisuru kohifutanjigyo jisshijokyo [The result of the survey on medical subsidy for children]. http://www.mhlw.go.jp/stf/houdou/2r9852000002xx3m.html. Accessed 28 Apr 2015 (In Japanese).

10. Skinner AC, Mayer ML. Effects of insurance status on children's access to specialty care: a systematic review of the literature. BMC Health Serv Res. 2007;7:194.

11. Davidoff A, Kenney G, Dubay L. Effects of the State Children's Health Insurance Program expansions on children with chronic health conditions. Pediatrics. 2005;116:e34-42.

12. Szilagyi PG, Dick AW, Klein JD, Shone LP, Zwanziger J, et al. Improved asthma care after enrollment in the State Children's Health Insurance Program in New York. Pediatrics. 2006;117:486-96.

13. Szilagyi PG, Holl JL, Rodewald LE, Yoos L, Zwanziger J, et al. Evaluation of New York State's Child Health plus: children who have asthma. Pediatrics. 2000;105:719-27.

14. Kane DJ, Zotti ME, Rosenberg D. Factors associated with health care access for Mississippi children with special health care needs. Matern Child Health J. 2005:9:S23-31

15. Zickafoose JS, Smith K, Dye C. Children with special health care needs in CHIP: access, use, and child and family outcomes. Acad Pediatr. 2015;15: S85-92.

16. Leibowitz A, Manning Jr WG, Keeler EB, Duan N, Lohr KN, et al. Effect of cost-sharing on the use of medical services by children: interim results from a randomized controlled trial. Pediatrics. 1985:75:942-51.

17. Higashi K, Itoh M, Toyokawa S, Kobayashi Y. Subsidy and parental attitudes toward pediatric health care in the Tokyo metropolitan area. Pediatr Int. 2016;58(2):132-8.

18. Bessho S. Kodomo no iryohijosei, tsuin, kenko [Subsidies for children, their access and health]. Shakai Hoshou Kenkyuu. 2012;47(4):413-30 (in Japanese).

19. Foundation for Growth Science. Projects of the Foundation for Growth Science. http://www.fgs.or.jp/business/. Accessed 17 Oct 2016 (In Japanese).

20. Schaller B. Gender-related differences in growth hormone-releasing pituitary adenomas. A clinicopathological study. Pituitary. 2002;5(4):247-53.

21. Sävendahl L, Blankenstein O, Oliver I, Thybo Christesen $H$, Lee $P$, et al. Gender influences short-term growth hormone treatment response in children. Horm Res Paediatr. 2012;77(3):188-94.

22. Nettle D. Women's height, reproductive success and the evolution of sexual dimorphism in modern humans. Proc Biol Sci. 2002;269:1919-23.

23. Hensley WE. Height as a basis for interpersonal attraction. Adolescence. 1994:29:469-74

24. Pawlowski B, Dunbar Rl, Lipowicz A. Tall men have more reproductive success. Nature. 2000;403:156

25. Suwa S, Tachibana K, Maesaka H, Tanaka T, Yokoya S. Longitudinal standards for height and height velocity for Japanese children from birth to maturity. Clin Pediatr Endocrinol. 1992:1:5-13.

26. McPherson M, Arango P, Fox H, Lauver C, McManus M, et al. A new definition of children with special health care needs. Pediatrics. 1998;102:137-40.

27. Information Center for Specific Pediatric Chronic Diseases, Japan. http:// www.shouman.jp/disease/. Accessed 08 Sept 2016 (In Japanese).

28. Carel JC, Ecosse E, Nicolino M, Tauber M, Leger J, et al. Adult height after long term treatment with recombinant growth hormone for idiopathic 
isolated growth hormone deficiency: observational follow up study of the French population based registry. BMJ. 2002;325:70.

29. Cutfield W, Lindberg A, Albertsson Wikland K, Chatelain P, Ranke MB, et al. Final height in idiopathic growth hormone deficiency: the KIGS experience. Acta Paediatr Int J Paediatr. 1999;88:72-5.

30. August $\mathrm{G}$, Julius J, Blethen $\mathrm{S}$. Adult height in children with growth hormone deficiency. Pediatrics. 1998;102:512-6.

31. Clayton PE, Cowell CT. Safety issues in children and adolescents during growth hormone therapy - a review. Growth Horm IGF Res. 2000;10:306-17.

32. Pérez VB, López-Siguero JP, Martínez G, Corripio R, Fernández JM, et al. A follow-up study to monitor adult height among spanish children with growth hormone deficiency who received biosimilar human recombinant growth hormone (Omnitrope ${ }^{\oplus}$ ) during a phase III clinical trial. Adv Ther. 2015;32:148-56.

33. Bryant J, Cave C, Mihaylova B, Chase D, McIntyre L, et al. Clinical effectiveness and cost-effectiveness of growth hormone in children: a systematic review and economic evaluation. Health Technol Assess. 2002;6:1-168.

34. Ekbote VH, Khadilkar V, Chiplonkar SA, Khadilkar A, Mughal Z. Low bone status in Indian growth hormone-deficient children. J Pediatr Endocrinol Metab. 2012;25:969-76.

35. Baars J, Van den Broeck J, le Cessie S, Massa G, Wit JM. Body mass index in growth hormone deficient children before and during growth hormone treatment. Horm Res. 1997;49:39-45.

36. Sandberg DE, Bukowski WM, Fung CM, Noll RB. Height and social adjustment: are extremes a cause for concern and action? Pediatrics. 2004;114:744-50

37. Ross JL, Sandberg DE, Rose SR, Leschek EW, Baron J, et al. Psychological adaptation in children with idiopathic short stature treated with growth hormone or placebo. J Clin Endocrinol Metab. 2004;89:4873-8.

38. Visser-van Balen H, Sinnema G, Geenen R. Growing up with idiopathic short stature: psychosocial development and hormone treatment; a critical review. Arch Dis Child. 2006;91:433-9.

39. Chaplin JE, Kriström B, Jonsson B, Tuvemo T, Albertsson-Wikland K. Growth hormone treatment improves cognitive function in short children with growth hormone deficiency. Horm Res Paediatr. 2015. doi:10.1159/ 000375529.

40. Tanaka T, Hasegawa T, Ozono K, Tanaka H, Kanzaki S, et al. Effect of growth hormone treatment on quality of life in Japanese children with growth hormone deficiency: an analysis from a prospective observational study. Clin Pediatr Endocrinol. 2014;23:83-92.

41. Magnusson PK, Gunnell D, Tynelius P, Davey Smith G, Rasmussen F. Strong inverse association between height and suicide in a large cohort of Swedish men: evidence of early life origins of suicidal behavior? Am J Psychiatry. 2005;162:1373-5.

42. Asao K, Kao WH, Baptiste-Roberts K, Bandeen-Roche K, Erlinger TP, et al. Short stature and the risk of adiposity, insulin resistance, and type 2 diabetes in middle age: the Third National Health and Nutrition Examination Survey (NHANES III), 1988-1994. Diabetes Care. 2006;29:1632-7.

43. Batty GD, Shipley MJ, Gunnell D, Huxley R, Kivimaki M, et al. Height, wealth, and health: an overview with new data from three longitudinal studies. Econ Hum Biol. 2009;7:137-52.

44. Power C, Manor O, Li L. Are inequalities in height underestimated by adult social position? Effects of changing social structure and height selection in a cohort study. BMJ. 2002;325:131-4.

45. Tokyo Metropolitan Government. Iryohijosei [Medical subsidies]. http:// www.fukushihoken.metro.tokyo.jp/iryo/josei/index.html . Accessed 28 Apr 2015.(In Japanese)

\section{Submit your next manuscript to BioMed Central and we will help you at every step:}

- We accept pre-submission inquiries

- Our selector tool helps you to find the most relevant journal

- We provide round the clock customer support

- Convenient online submission

- Thorough peer review

- Inclusion in PubMed and all major indexing services

- Maximum visibility for your research

Submit your manuscript at www.biomedcentral.com/submit
Biomed Central 